Article

\title{
Young People's Perceptions of the Influence of a Sport-for-Social-Change Program on Their Life Trajectories
}

\author{
Rob Cunningham, Anne Bunde-Birouste *, Patrick Rawstorne and Sally Nathan \\ School of Public Health and Community Medicine, University of New South Wales, Sydney, NSW 2052, Australia; \\ E-Mails: robert.cunningham@unsw.edu.au (R.C.), ab.birouste@unsw.edu.au (A.B.-B.), p.rawstorne@unsw.edu.au (P.R.), \\ s.nathan@unsw.edu.au (S.N.) \\ * Corresponding author
}

Submitted: 25 January 2020 | Accepted: 8 June 2020 | Published: 17 August 2020

\begin{abstract}
Sport-for-social-change programs focusing on enhancing young people's personal and social development emerged in the early to mid-2000s. Children and adolescents who participated in early programs are now adults, providing an opportunity to examine whether these programs have had any influence on their life trajectories. The Football United program has been operating in Sydney, Australia, since 2006 and is used as a case study in this article. This qualitative study draws on 20 interviews conducted in 2018 with a diverse sample of past participants of the program. Key findings were that participants perceived that the relationships they formed at Football United have had a substantial impact on their life trajectories, including influencing education and career decisions. These relationships were found to increase participants' social capital, creating diverse connections with people and institutions within and external to their geographical communities. This study also found participants embraced a long-term commitment to 'give back' to their local geographical, cultural, and ethnic communities, which they attributed to their participation in the program.
\end{abstract}

\section{Keywords}

Australia; football; social capital; sport; sport-for-social change; Sydney; youth development

\section{Issue}

This article is part of the issue "Sport for Development: Opening Transdisciplinary and Intersectoral Perspectives" edited by Pascal Delheye (Ghent University, Belgium), Kirsten Verkooijen (Wageningen University \& Research, The Netherlands), Dan Parnell (University of Liverpool, UK), John Hayton (Northumbria University, UK) and Reinhard Haudenhuyse (Vrije Universiteit Brussel, Belgium).

(C) 2020 by the authors; licensee Cogitatio (Lisbon, Portugal). This article is licensed under a Creative Commons Attribution 4.0 International License (CC BY).

\section{Introduction}

Youth focused sport-for social-change (SFSC) programs have gained prominence over the past two decades as part of a global movement in using sport as a tool to tackle complex social and development problems (Coakley, 2011; Coalter, 2013; Kay, 2012). SFSC programs often focus on disadvantaged and vulnerable groups such as "at-risk youth, indigenous communities, recently arrived refugees, and culturally and linguistically diverse communities" (Sherry, Schulenkorf, \& Chalip, 2015). These groups of young people often face discrimination and social exclusion within their geographic communities, and demonstrate poorer outcomes in education, employment, and health (United Nations Department of Economic and Social Affairs, 2016). Youth-focused SFSC programs leverage the global popularity of sport to incorporate life-skills, education, and capacity building elements with the aim of positively influencing the personal and social development of participants (Holt et al., 2017).

Research into the impact and outcomes of youthfocused SFSC programs suggest they have the potential to contribute to building participants' life-skills, including 
enhancing social, emotional and behavioural capabilities (Bunde-Birouste et al., 2012; Holt et al., 2017; Nathan et al., 2013; Weiss, Bolter, \& Kipp, 2016; Whitley, Massey, \& Farrell, 2017; Whitley, Massey, \& Wilkison, 2018). Studies also suggest these programs have the potential to positively influence participants' social connectedness through facilitating relationships outside of their cultural, ethnic, and geographical communities (Spaaij, 2012, 2013). Longer-term impact studies of SFSC programs are limited, perhaps due to the difficulty in following up with this population in the years after their participation. However, given some programs have now been in place for up to 15 years, longer term impacts can be examined (Hoekman, Schulenkorf, \& Welty Peachey, 2018).

The Football United (FUn) program, which is the focus of the current article, provides opportunities to explore whether and how a youth-focused SFSC program helped influence the life trajectories of participants. The FUn program has been operating for thirteen years and works with young people from disadvantaged and diverse backgrounds, with the aim of positively influencing participants' personal and social development (Bunde-Birouste, 2013; Bunde-Birouste et al., 2012; Nathan et al., 2010, 2013). FUn has demonstrated shortterm impacts such as positively influencing participants' sense of self, pro-social behaviours, and engagement within school (Bunde-Birouste, 2013; Bunde-Birouste et al., 2012; Nathan et al., 2010, 2013). However, the FUn program also aims to have a positive impact on participants' long-term development and life trajectories (Bunde-Birouste, 2013) yet, to date, such longer term follow-up research has not been undertaken.

This study examines the experiences of a sample of FUn program participants, at a minimum six years after initial program engagement when they were still young adults, yet education and career trajectories were likely to be established. The study explores whether and how participants perceived their involvement in FUn has influenced their life trajectories and what aspects of the program, if any, may have contributed to their decisions, pathways, and achievements. The findings of this study are an important step in starting to understand how SFSC programs may positively influence young people's longerterm life-paths.

\subsection{Theoretical Lens}

Social capital theory was identified as an analytical lens after the interviews were conducted and following an initial inductive thematic analysis (see Section 2). Social capital theory was chosen as FUn was initially created with the goal of bringing people together through football, highlighting a commitment to creating social connections within and external to the participating young people's cultural, ethnic and geographical communities (Bunde-Birouste, 2013; Bunde-Birouste et al., 2012; Nathan et al., 2010, 2013). The program goals (see Section 2) also align with key concepts in social capital theory, described in further detail below. The study aims to examine how participants' life trajectories may have been influenced by the networks of social relationships established through their involvement in FUn.

Social capital is based on the concept that 'relationships matter'; it is about the connections we make with others and the value of these relationships (Field, 2003, p. 1). Social capital allows for a deep analysis of the importance of social ties across communities and society. The analysis in this article is influenced by several key scholars in social capital, including Putnam's (2000) view of social capital suggesting that "social networks have value...and refers to connections among individuals, social networks and norms of reciprocity and trustworthiness that arise from them" (Putnam, 2000, p. 19). Bourdieu's (1986) and Coleman's (1994) conceptualisation of social capital and its relationship to disadvantaged groups within society, is also relevant for this study and is detailed later in this section. As most participants in the current study arrived in Australia as refugees, this article is also influenced by scholars who have embraced a social capital framework examining the resettlement experiences of refugees. In particular Ager and Strang (2004) used social capital theory to highlight the importance of social connections within their 'indicators of integration' framework, suggesting that relationships and connection are critical in the resettlement and life trajectories of refugees (Ager \& Strang, 2004). Ager and Strang's framework draws on social capital theorists such as Putnam (2000) and Woolcock (2001) to distinguish between three types of social connection that influence successful integration of refugees within their host communities; social bonds, social bridges, and social links.

\subsubsection{Bonding and Bridging Social Capital}

Bridging social capital refers to creating relationships with heterogeneous groups, and is seen as having societal advantages when compared to bonding social capital as it helps to build relationships among diverse individuals and groups, guarding against exclusion, and has been argued to promote social cohesion (Portes, 1998; Putnam, 2000). Putnam describes 'bonding' as a sociological superglue which reinforces and strengthens existing networks in comparison with 'bridging' being the "WD-40 that binds communities together" (Putnam, 2000 , p. 23). Ager and Strang (2008) suggest bridging social capital helps create social cohesion amongst people from different cultural, ethnic, and religious backgrounds, creating opportunities to build understanding and social connection.

\subsubsection{Linking Social Capital}

Woolcock has been credited with extending Putnam's concepts of 'bonding and bridging,' coining the term 'linking social capital' to describe vertical connections that link members of a community to individuals, groups and 
institutions outside of their local community (Woolcock, 2001). Linking social capital is seen as a mechanism that can unlock opportunities, resources, and power within society by creating relationships between "unlike people in dissimilar situations" (Woolcock, 2001, p. 13). Through these personal and institutional relationships diverse and disadvantaged groups in society can gain access to a range of resources outside of their cultural, ethnic, and geographical communities (Szreter \& Woolcock, 2004; Woolcock, 2001). Linking social capital is also argued to be more important for diverse populations such as migrants and refugees when resettling in a new country, allowing connections to be established with educational, occupational and social institutions (Ager \& Strang, 2004, 2008). Linking social capital is not only crucial in the period of resettlement, it can also influence positive long-term educational, occupational and social outcomes (Ager \& Strang, 2004, 2008; Correa-Velez, Gifford, \& Barnett, 2010; CorreaVelez, Gifford, McMichael, \& Sampson, 2016).

The descriptions of social capital above provides an overview of the potential to enhance social capital for disadvantaged and diverse groups. Bourdieu (1986) however views social capital as an asset of and for the privileged and powerful within society, and that it is used as a resource to maintain such power. For Bourdieu disadvantaged individuals and groups do not have the same access to social capital resources as the privileged and powerful do, which perpetuates ongoing societal inequities (Bourdieu, 1986). Aligned with this view, using SFSC programs to facilitate social capital has also been criticised as a "micro-solution to macro-problems" (Darnell, 2012, p. 95), which fails to take into account complex social, cultural and institutional forces that continue to oppress disadvantaged and minority communities (Blackshaw \& Long, 2005; Darnell, 2012; Kay \& Bradbury, 2009; Spaaij, 2009). Also, some SFSC scholars have suggested that developing social capital through SFSC programs serves only to legitimise an unjust neoliberal ideology that has weakened the public system and increased inequity (Blackshaw \& Long, 2005; Darnell, 2012; Kay \& Bradbury, 2009; Spaaij, 2009). In this context, Darnell (2012) argued that facilitating social capital through SFSC programs help individuals succeed in a largely unjust society and failed to address issues of structural inequality within society.

Other SFSC researchers and scholars acknowledge the concerns relating to failure to address structural inequity, while also suggesting these programs have the potential to enhance participants' social capital (Adams, Harris, \& Lindsey, 2017; Coalter, 2010; Sherry, 2010; Spaaij, 2012, 2014; Welty Peachey, Cohen, Borland, \& Lyras, 2011). For example, Spaaij (2012) examined the building of social and cultural capital within a youthfocused SFSC program in Brazil. While acknowledging that the wider social context and lived experience of young people translates into inequitable access to social capital resources, Spaaij's study also demonstrated that SFSC programs ability to build social and cultural capital (Spaaij, 2012). Spaaij suggests this is achieved by young people developing relationships with 'institutional agents' such as mentors who have the capacity to link participants to opportunities and resources outside of their geographic and cultural community (Spaaij, 2012). Both Spaaij (2012) as well as Adams et al. (2017), use Coleman's conceptualisation of social capital to demonstrate that social capital is not only a resource accessible to the rich and powerful, but also can benefit disadvantaged and diverse groups within society in some contexts. Coleman states social capital can be viewed as:

The set of resources that inhere in family relations and in community social organisations and that are useful for the cognitive or social development of a child or young person. These resources differ for different persons and can constitute an important advantage for children and adolescents in the development of their human capital. (Coleman, 1994, p. 300)

Coleman's conceptualisation of social capital is important for this study as it relates directly to the development of young people, and suggests access to social capital resources is built on the strength of family and community relationships, not only pre-determined by just privilege, power or status within society (Coleman, 1994).

In this article we examine whether participants viewed their life trajectories as being in part influenced by bridging and linking relationships, in particular the relationships created through their involvement with the FUn program. The article also explores in what ways these relationships operated to influence their life trajectories.

\section{Methods}

A qualitative inquiry using in-depth interviews was undertaken with 20 former participants in the FUn program. Underpinning this study was a strengths-based approach, with a focus on examining participants' current and past personal and social resources and assets that positively influenced their life trajectories (Zimmerman, 2013). The research team included a $\mathrm{PhD}$ candidate and three supervisors from the University of New South Wales. It is important here to note the past experiences and knowledge of the research team and their potential impact on the interpretation of the findings. The first author, Rob Cunningham, has often used SFSC programs in his 20 years field experience working with young people. The second author, Anne Bunde-Birouste, is the founder and director of the FUn program. These experiences could potentially lead to 'overreach' when it comes to analysing potential impacts of this program, a valid criticism of past SFSC research and evaluation (Coalter, 2010, 2015; Darnell, 2012; Kay \& Bradbury, 2009). However, two authors (Patrick Rawstorne and Sally Nathan) are not involved in the delivery of SFSC programs. The make-up of this research team allowed for reflexivity and guarded 
against overreach. Braun and Clarke (2019, p. 595) state "assumptions and positionings are always part of qualitative research," and what matters is the ability of researchers to be reflexive and understand their own assumptions and how such assumptions may inadvertently or otherwise influence the research process. Reflexivity was achieved in the current study through frequent team meetings during data collection, data analysis and theme development. During this process, the research team actively sought discrepant or negative cases to ensure the reporting of findings was reflective of the entire data set. This approach is consistent with Braun and Clarke (2019) who state that working in a team should be "collaborative and reflexive, designed to develop a richer more nuanced reading of the data" (Braun \& Clarke, 2019, p. 594).

\subsection{The Program: FUn}

Following two years of background research and pilot activities, FUn began in 2006 with the aim of supporting refugee and newly arrived young people in their resettlement into local communities in Sydney. This support included providing opportunities to participate in football activities with the goal of bringing people together, fostering social inclusion and cohesion (Bunde-Birouste, 2013; Nathan et al., 2010, 2013). The program has since evolved to become a multi-strategic capacity-building program to engage with disadvantaged young people from all cultural backgrounds. The FUn program has four key areas of focus.

The first is to engage young people through sport. This occurs through specially designed activities that incorporate a positive youth development and life skills curriculum nested within football activities providing opportunities to develop personal, social and leadership skills. Regular program sessions are run during weekends, and after school, and include special events such as gala days, and school holiday camps. These activities are free, safe, and accessible opportunities for young people from diverse and disadvantaged backgrounds to play football. A complementary goal of the football activities and associated curriculum is the development of mentoring relationships between coaches, volunteers, and players. Mentoring is considered an integral mechanism of the program and is considered to have a significant influence on the lives of participants (Bunde-Birouste, 2013; Bunde-Birouste et al., 2012).

The second area of focus concerns personal and professional development through more structured activities. Young people and their families can participate in a range of courses and workshops in coaching, refereeing, mentoring, life-skills, leadership, first aid, project management and volunteering. This learning is then applied as participants engage in various roles within the FUn program which includes the opportunity to start as a participant and progress to a youth leader and coach (Bunde-Birouste, 2013; Bunde-Birouste et al., 2012).
The third area of focus is the linkages between the program participants and a range of community and organisational stakeholders. These links between program participants and institutions and agencies in the education, community services, government, and corporate sectors is viewed by FUn as being critical in providing their young participants with opportunities and networks for longer-term development (Bunde-Birouste, 2013; Bunde-Birouste et al., 2012).

The fourth area of focus is to create awareness within society of the challenges faced, but also the strengths of young people from disadvantaged and diverse backgrounds. Awareness raising is achieved through advocacy and research, with the aim of positively influencing changes to government policy and public perceptions (Bunde-Birouste, 2013; Bunde-Birouste et al., 2012).

Previous research into the impact of FUn has found the program has consistently produced quantifiable improvements in the lives of individuals in the short term (Bunde-Birouste, 2013; Bunde-Birouste et al., 2012; Nathan et al., 2010, 2013). This research, conducted with FUn participants at the time of their involvement in the program and up to one year after engagement, demonstrated a positive impact on young people's sense of self, and appreciation for and engagement with peers from diverse backgrounds and pro-social behaviour (Bunde-Birouste, 2013; Bunde-Birouste et al., 2012; Nathan et al., 2010, 2013). Results also indicated connections between participating in FUn and learning English, positive engagement with school, and building self-confidence (Bunde-Birouste, 2013; Bunde-Birouste et al., 2012; Nathan et al., 2013). This current study is the first research to explore FUn's influence on program participants in the longer-term.

\subsubsection{Sampling Approach}

A purposive sampling design (Patton, 2015) was used to recruit former FUn participants. FUn staff members were asked to nominate former program participants who had been involved in the program for any length of time between 2009-2012, allowing for a minimum six-year gap between participants' initial involvement in the program and participation in the study. This timeframe is important as the current study aims to examine participants' perceptions of whether FUn had any influence on their life trajectories. A six-year gap ensured all participants were young adults at the time of this study. This enabled participants during their interviews to reflect on a range of life experiences post their involvement with the program, and whether FUn had any influence on their life trajectories.

FUn staff members were asked to nominate former participants with varying experiences of the program, including the length of time they participated and their type of involvement. The purpose of seeking these variations was to enable an examination of whether the type and length of involvement in the program had any in- 
fluence on potential long-term development for participants. Sixteen former FUn participants who were nominated by FUn team members were contacted by e-mail to ask if they were interested in participating. Ten FUn participants from this sample group agreed to an initial round of interviews. The remainder of the interviewees were recruited via snowball sampling; all 10 participants were asked to nominate a FUn peer that had also started attending the program between 2009-2012. This resulted in the recruitment of ten additional participants.

\subsubsection{Data Collection}

Interviews were conducted either face to face or via Skype depending on factors such as location or preference of the interviewee. Interviews covered a range of topics including life experiences prior to being introduced to FUn, their experiences as a participant in the program, and their life trajectories after the program. A flexible semi-structured approach to interviewing was used (Patton, 2015). While the interviewer guided the discussion towards the overall research aims of the study, flexibility enabled the exploration of unique insights and ensured the experience of participants was prioritised and respected (Nathan, Newman, \& Lancaster, 2018). The semi-structured interview allowed for participants to provide in-depth accounts of their experiences prior to, within, and since their involvement with the program.

\subsubsection{Data Analysis}

This study initially employed an inductive thematic approach to analysis, influenced by the work of Braun and Clarke (2006) and Terry, Hayfield, Clarke, and Braun (2017), undertaking a six-phase analytic process. Familiarisation of the data set began during the interview process; the audio recordings of each interview were listened to multiple times helping to create early analytic observations. This process provided added flexibility, allowing for interview questions to be shaped and influenced by earlier interviews. Once interviews were complete, familiarisation of the entire data set began, which involved reading and re-reading transcripts multiple times. Going back to the original audio recordings allowed for a full immersion and engagement with the data. The research team also returned to the original data set multiple times to confirm that the coding and theme development remained true to the voices of participants in the study (Terry et al., 2017).

Coding of the entire data set was also conducted inductively. At this early stage coding was inclusive; ensuring all data of interest was highlighted and recorded. The research team met to examine codes, those with similar meanings were integrated, some codes required further development, and others were deleted if deemed to have little relevance to the research questions. Theme development commenced following completion of coding for the entire dataset. As per Terry et al. (2017), the study's research aim was used as a guide for theme development. During this phase codes were examined, those that demonstrated a pattern of meaning were grouped together or combined, and a number of initial 'candidate themes' were identified (Braun, Clarke, \& Terry, 2015, p. 102). Theme development was an extensive process for the research team, with reflexivity achieved through frequent team meetings to agree on key themes and meaning and resulted in returning to the data set many times to look for discrepant cases. At the stage of theme refinement, the research team agreed that applying a theoretical framework would provide a platform for a more theoretically informed and deeper analysis of the data. The research team examined and rejected a number of theoretical frameworks prior to committing to social capital theory which was more aligned to the candidate themes and research questions.

\subsubsection{Ethics}

Ethical approval for this study was obtained from the Human Research Ethics Committee at the University of New South Wales. Participants of the study provided written consent prior to interviews. To protect the identity of participants, their names and other personal details have been changed.

\section{Results and Discussion}

This section presents findings from the data analysis of participant interviews. Table 1 presents a description of participant characteristics including cultural and ethnic backgrounds, the length and type of involvement in the FUn program, their education and employment achievements, and their current involvement within their geographical, cultural, and ethnic communities.

As can be seen in Table 1, a majority of participants in this study arrived in Australia as refugees. Prior to their settlement in Australia their life histories were characterised by trauma, loss, and grief. Participant histories of displacement and resettlement are important in this study. As we will argue throughout this article the lived experience of participants influenced their experience within the program, and also shaped how the program may have influenced their life trajectories.

Participants in the current study were introduced to the FUn program as children or adolescents. Participants' type and length of involvement in the program was influenced by the structure and opportunities within the FUn program at their school. It is important to note that many SFSC programs run for a defined period and often do not extend beyond a few months (Spaaij, 2011). FUn differs from this model and offers ongoing engagement and the ability for participants to progress to facilitators, youth leaders and coaches within the program. While the aim of the study had been to recruit a sample of participants with varying length and type of experience with the program, it was difficult to contact 
Table 1. Participant characteristics and experiences.

\begin{tabular}{|c|c|c|c|c|c|}
\hline $\begin{array}{l}\text { Pseudonym } \\
\text { and gender } \\
(\mathrm{M} / \mathrm{F})\end{array}$ & $\begin{array}{l}\text { Country } \\
\text { of birth }\end{array}$ & $\begin{array}{l}\text { Refugee } \\
\text { status }\end{array}$ & FUn involvement & $\begin{array}{l}\text { Current } \\
\text { study/occupation }\end{array}$ & $\begin{array}{l}\text { Current involvement in } \\
\text { community activities } \\
\text { (includes cultural, ethnic } \\
\text { and geographic communities) }\end{array}$ \\
\hline Shirisha (F) & Nepal & Yes & $\begin{array}{l}\text { 2010-Present } \\
\text { Participant } \\
\text { Youth leader/coach }\end{array}$ & Nurse & $\begin{array}{l}\text { SFSC facilitator } \\
\text { Leader of a youth dance class } \\
\text { Youth events coordinator } \\
\text { Television presenter }\end{array}$ \\
\hline Grace (F) & Ghana & Yes & $\begin{array}{l}\text { 2008-Present } \\
\text { Participant } \\
\text { Youth leader/coach }\end{array}$ & $\begin{array}{l}\text { Full-time student in } \\
\text { Social Science/ } \\
\text { Criminology } \\
\text { Part-time employee } \\
\text { in customer service }\end{array}$ & $\begin{array}{l}\text { SFSC facilitator } \\
\text { Youth group coordinator } \\
\text { Food bank volunteer } \\
\text { Refugee Council presenter }\end{array}$ \\
\hline Mohamed (M) & Guinea & Yes & $\begin{array}{l}\text { 2010-Present } \\
\text { Participant } \\
\text { Youth leader/coach }\end{array}$ & $\begin{array}{l}\text { Full time student in } \\
\text { Health Science/ } \\
\text { Physiotherapy } \\
\text { Part time employee } \\
\text { in customer service } \\
\text { Semi-professional } \\
\text { footballer }\end{array}$ & SFSC facilitator \\
\hline $\operatorname{Amar}(\mathrm{M})$ & Bosnia & Yes & $\begin{array}{l}\text { 2009-2011 } \\
\text { Participant }\end{array}$ & $\begin{array}{l}\text { Trade/business } \\
\text { owner }\end{array}$ & $\begin{array}{l}\text { Participation in } \\
\text { Bosnian community } \\
\text { events }\end{array}$ \\
\hline Zaida (F) & Iraq & Yes & $\begin{array}{l}\text { 2009-2012 } \\
\text { Participant }\end{array}$ & Allied health & $\begin{array}{l}\text { No current community } \\
\text { activities }\end{array}$ \\
\hline Kirra (F) & $\begin{array}{l}\text { Australia } \\
\text { (Indigenous) }\end{array}$ & No & $\begin{array}{l}\text { 2011-Present } \\
\text { Participant } \\
\text { Youth leader/coach }\end{array}$ & Teacher & $\begin{array}{l}\text { Leader of youth dance } \\
\text { group } \\
\text { Responsible for } \\
\text { implementing SFSC } \\
\text { program }\end{array}$ \\
\hline Aamira (F) & Kenya & Yes & $\begin{array}{l}\text { 2006-2014 } \\
\text { Participant } \\
\text { Youth leader/coach }\end{array}$ & $\begin{array}{l}\text { Refugee } \\
\text { resettlement worker } \\
\text { Full time student } \\
\text { in International } \\
\text { Development }\end{array}$ & $\begin{array}{l}\text { Creator and director of social } \\
\text { change initiative } \\
\text { National Council Refugee } \\
\text { Women Committee member }\end{array}$ \\
\hline Jose (M) & Australia & No & $\begin{array}{l}\text { 2008-2014 } \\
\text { Participant }\end{array}$ & International logistics & $\begin{array}{l}\text { Volunteer at church and } \\
\text { youth groups }\end{array}$ \\
\hline Brev (M) & Iran & Yes & $\begin{array}{l}\text { 2009-Present } \\
\text { Participant } \\
\text { Youth leader/coach }\end{array}$ & $\begin{array}{l}\text { Professional } \\
\text { footballer } \\
\text { Police officer trainee }\end{array}$ & SFSC facilitator \\
\hline Medi (F) & Congo & Yes & $\begin{array}{l}\text { 2008-2012 } \\
\text { Participant }\end{array}$ & $\begin{array}{l}\text { Full time student in } \\
\text { Education } \\
\text { Employed in childcare }\end{array}$ & $\begin{array}{l}\text { Facilitates information and } \\
\text { education sessions for } \\
\text { Congolese community }\end{array}$ \\
\hline Aida (F) & Ethiopia & Yes & $\begin{array}{l}\text { 2009-2016 } \\
\text { Participant } \\
\text { Youth leader/coach }\end{array}$ & $\begin{array}{l}\text { Full time student in } \\
\text { International Studies } \\
\text { (Human Rights) }\end{array}$ & $\begin{array}{l}\text { Supports and coordinates } \\
\text { community events in the } \\
\text { Ethiopian community }\end{array}$ \\
\hline
\end{tabular}


Table 1. (Cont.) Participant characteristics and experiences.

\begin{tabular}{|c|c|c|c|c|c|}
\hline $\begin{array}{l}\text { Pseudonym } \\
\text { and gender } \\
(\mathrm{M} / \mathrm{F})\end{array}$ & $\begin{array}{l}\text { Country } \\
\text { of birth }\end{array}$ & $\begin{array}{l}\text { Refugee } \\
\text { status }\end{array}$ & FUn involvement & $\begin{array}{l}\text { Current } \\
\text { study/occupation }\end{array}$ & $\begin{array}{l}\text { Current involvement in } \\
\text { community activities } \\
\text { (includes cultural, ethnic } \\
\text { and geographic communities) }\end{array}$ \\
\hline $\operatorname{Ram}(\mathrm{M})$ & Bhutan & Yes & $\begin{array}{l}\text { 2010-2014 } \\
\text { Participant } \\
\text { Youth leader/coach }\end{array}$ & $\begin{array}{l}\text { Electrical engineer } \\
\text { Youth and sports } \\
\text { coordinator }\end{array}$ & $\begin{array}{l}\text { Sydney Bhutanese } \\
\text { Community Executive } \\
\text { Committee member }\end{array}$ \\
\hline Amira (F) & Syria & Yes & $\begin{array}{l}\text { 2011-2012 } \\
\text { Participant }\end{array}$ & Medical receptionist & $\begin{array}{l}\text { Provides translation and } \\
\text { interpretation services }\end{array}$ \\
\hline Adama (M) & Congo & Yes & $\begin{array}{l}\text { 2012-Present } \\
\text { Participant } \\
\text { Youth leader/coach }\end{array}$ & $\begin{array}{l}\text { Finance } \\
\text { Recently completed } \\
\text { a degree in } \\
\text { Commerce/Law }\end{array}$ & $\begin{array}{l}\text { Volunteer at the Migrant } \\
\text { Resource Centre, Red Cross } \\
\text { SFSC facilitator } \\
\text { Football coach }\end{array}$ \\
\hline Kamelah (F) & Afghanistan & Yes & $\begin{array}{l}\text { 2012-2014 } \\
\text { Participant }\end{array}$ & $\begin{array}{l}\text { Full-time bachelor } \\
\text { student in Health } \\
\text { Science }\end{array}$ & $\begin{array}{l}\text { Afghan women's football } \\
\text { team Manager } \\
\text { Participation in Afghan } \\
\text { community events }\end{array}$ \\
\hline Aliyah (F) & Sudan & Yes & $\begin{array}{l}\text { 2012-2014 } \\
\text { Participant }\end{array}$ & $\begin{array}{l}\text { Full-time student in } \\
\text { Social Sciences } \\
\text { International football } \\
\text { scholarship }\end{array}$ & $\begin{array}{l}\text { Football club } \\
\text { Community events }\end{array}$ \\
\hline Abdul (M) & Afghanistan & Yes & $\begin{array}{l}\text { 2012-2014 } \\
\text { Participant }\end{array}$ & Trade apprenticeship & Football club \\
\hline Majeeda (F) & Australia & No & $\begin{array}{l}\text { 2009-2012 } \\
\text { Participant }\end{array}$ & $\begin{array}{l}\text { Full-time student in } \\
\text { Social Work } \\
\text { Employed in childcare }\end{array}$ & Nil \\
\hline Lana (F) & Iraq & Yes & $\begin{array}{l}\text { 2009-2013 } \\
\text { Participant } \\
\text { Youth leader/coach }\end{array}$ & Allied health & $\begin{array}{l}\text { Young women's } \\
\text { leadership programme }\end{array}$ \\
\hline Asim (M) & South Sudan & Yes & $\begin{array}{l}\text { 2012-2015 } \\
\text { Participant } \\
\text { Youth leader/coach }\end{array}$ & Performing arts & Nil \\
\hline
\end{tabular}

Note: Pseudonyms have been used for all participants in this study.

those with minimal involvement, and those with moderate and intensive involvement were more likely to agree to be interviewed.

While the sample of participants did not include those with minimal experience, it did consist of young people who had different experiences within the program. Five participants described their involvement within the programme as lasting two years, six participants as lasting three to four years, and three participants between six to eight years. Six participants described their involvement as ongoing, undertaking a role within FUn at the time of their interview. This ongoing involvement often incorporated extended breaks where they could not maintain involvement due to other commitments. As the table indicates participants who were involved with FUn for a shorter duration were more likely to be involved as participants. While those with longer term involvement were more likely to have progressed to youth leaders and coaches within the program. All participants were aged between 21 and 28 years of age at the time of their interviews, and the gender split was $12 \mathrm{fe-}$ male and 8 male participants.

At the time of being interviewed for this study, all twenty participants were either in full time education or 
employment, in professions as varied as teaching, allied health, international development, electrical engineering, finance, and the arts. 18 participants reported being active in their local communities either through playing and coaching sport, creating their own SFSC programs, facilitating youth programs, or organising and participating in community events. The following sections focus on participants' perceptions of how the FUn program influenced their life trajectories.

\subsection{Relationships with Peers: Bridging Social Capital}

In this section we examine participants' perceptions that FUn facilitated long-term relationships with their adolescent peers across cultural and ethnic divides within their geographical communities. We argue that most participants had limited social capital (Putnam, 2000) at the time of their introduction to FUn, and through their participation in the program were able to create new social networks that increased their sense of belonging. Specifically, we use the concept of bridging social capital (Putnam, 2000) to understand how a sense of belonging experienced by participants not only assisted them at the time of their involvement in the program, but also potentially influenced their life trajectories.

We use Grace, Shirisha, Kirra and Amar's experience in relation to bridging social capital, specifically their search for a sense of belonging, and the role FUn played in meeting this need. Grace spent the first 13 years of her life in a refugee camp and explained during her interview that this undermined her sense of belonging: "It's really hard to feel like you belong anywhere...we all [want] to belong, we all [want] to fit in, we all to want to feel at home....I've always... wanted that feeling." Growing up in the camp, Grace explained that she had strong relationships with family and friends; however, the insecure and unstable nature of life as a displaced person did not allow her to develop a sense of belonging. Grace shared that her childhood experience created a strong desire to one day live in a place she could call home, one that offered safety, stability, and most of all a sense of belonging.

While resettlement in Australia provided hope to Grace, the reality was that she initially still felt socially isolated and disconnected from her adolescent peers which initially prevented her from achieving a sense of belonging. Grace described her parents being overprotective when it came to participating in social activities with her adolescent peers. This was true for a number of participants who described their care-givers as being fearful of their new surroundings, preventing them from developing social relationships with their peers, particularly those from different cultural and ethnic backgrounds. The little contact Grace had with her peers at school was characterised by racism: "I was called monkey, ape, everything, it was racial, it was the fact that I couldn't speak English." This racism and lack of social connection undermined not only Grace's resettlement experience, but her well-being and actions towards others. Grace described getting into fights and undertaking illegal activities. At this point Grace had little social capital to draw upon to help her meet the challenges of her new environment, and her lack of social connection with her peers undermined the sense of belonging she had been searching for in Australia.

It was at this time that FUn came into Grace's life; she was given permission to attend FUn program activities as they involved a sport, football, that her family had a deep connection to from their past. She explained that she and her father, siblings and friends would often play football in the refugee camp together and developed a shared love of the sport. Grace's introduction to FUn provided an opportunity to establish new friendships, and she shared that she was able to build positive social connections for the first time since her resettlement:

I went there and I played, and I made a lot of new friends....There was just a connection there for the first time I felt like there was hope. I feel some sort of connection to Australia, you know, to my new home in a way. (Grace)

Grace provided various accounts of how FUn activities such as camps and tournaments allowed her to participate alongside other young people from a wide variety of cultural and ethnic backgrounds, including Anglo-Saxon Australians. This helped Grace and other participants build awareness of other cultural groups, as well as learning communication skills. Grace explained how participation in FUn was able to break down preconceived ideas she had about other groups of young people from different backgrounds to her own. Grace's experience was consistent with a number of other participants, for example Kirra and Amar discussed below and Shirisha who explains the impact FUn had on her developing relationships outside of her own cultural and ethnic community: "I made so many friends, they were different and they were so great, like they're still friends with me."

Shirisha and Grace established long-term, positive friendships that continue today. Grace continued in her interview to detail how important these social connections were: "It's positive because you feel connected and you feel like you belong, that sense of belonging in that space is so important and FUn offered me that."

Grace, Shirisha, and several other participants newfound sense of belonging was achieved by the creation of bridging social capital, creating and sustaining relationships with young people from outside of her cultural and ethnic community (Putnam, 2000). This was important as prior to their engagement with FUn the little social capital they were able to draw upon was through bonding relationships with a few family and friends from within their own ethnic and cultural communities. While these bonding relationships offered support, they could not help participants integrate into a society made up of many different ethnic and cultural groups, particularly 
the dominant cultural group of Anglo-Saxon Australians. In facilitating these new relationships FUn created an environment that promoted social connections amongst previously disconnected groups of young people. As social capital theory suggests bridging social capital was critically important for participants as it helped "create relationships across cultural and ethnic divides" (Putnam, 2000 , p. 23). This allowed Grace, Shirisha and other participants to break down cultural barriers that were preventing them from successfully adapting and integrating into their new geographical communities.

While participants perceived FUn as providing a sense of belonging by facilitating social connections at the time of their resettlement, a number of participants explained that this sense of belonging and connections also impacted their life trajectories. Several participants including Grace, Kirra and Amar explained that prior to their involvement with FUn they were at risk of making poor decisions that they believed would have negatively impacted their future development. These participants often spoke about the 'two roads' they could have gone down, the first involving illegal activities, conflict, and withdrawal from school and/or career opportunities. These participants explained that it was the relationships they formed through FUn that helped them choose a second road that ultimately led to social connection and engagement in school, career, and community.

Kirra who currently works as a teacher and is involved in creating her own SFSC program, explains she may have chosen a different path in life without the sense of belonging she found in FUn: "There's no way that I would have stayed on track, not when I look at where the people that I was hanging out with are now...drugs, crime." Amar who currently owns his own trade business and actively participates in local Bosnian events in his community, echoes Kirra's experiences: "FUn came along and then that got me away from those bad friends...like it kept me on a straight path." Kirra and Amar's perceptions are important as they are two of only three participants that were born in Australia, demonstrating that FUn's ability to create a sense of belonging through social connections went beyond those young people resettling in Australia. At the time of their introduction to FUn both Kirra and Amar had an existing social network of young people within their geographic communities, however these relationships may be viewed as negative social capital with a potential to undermine a positive life trajectory (Neale, Tompkins, \& Strang, 2018). Through their introduction to FUn they can be seen to have established a new set of social relationships, creating bridging social capital to others outside their existing community of friendships which they perceived as positively influencing their life trajectories.

Grace has recently completed a bachelor's degree in the social sciences. She is considering continuing study with a master's degree and has the goal to achieve social change through employment in the community development field. Grace is also heavily involved in her local geographic, cultural, and ethnic communities in a range of part time employment and voluntary roles. These roles include working as a SFSC facilitator, speaker for a refugee council, and volunteering in the operation of a food bank for disadvantaged members of the community. Grace credits the relationships she established at FUn and the sense of belonging it created, for what she has achieved today. Grace suggests FUn changed the trajectory of her life: "Coming here [Australia] I was offered two options....To go off the rails and do everything but good...then FUn was there. They offered the alternative and I took that alternative."

Grace and other participants believed that FUn played an instrumental role in their resettlement experiences and potential life trajectories. These findings are supported by social capital literature that has focussed on successful resettlement and long-term outcomes for young people from refugee backgrounds (Ager \& Strang, 2004, 2008; Correa-Velez et al., 2010). This literature argues that for young people from a refugee background, a sense of belonging is a critical social determinant of both well-being and successful resettlement in the long-term (Correa-Velez et al., 2010). Ager and Strang's model of integration suggests that the social connections formed through bridging social capital is one factor that can influence long-term education, employment, housing, and health outcomes (Ager \& Strang, 2004). This relationship between bridging relationships, sense of belonging, and successful long-term resettlement outcomes is important. It supports the findings of this study, that FUn's facilitation of bridging social capital may have not only supported resettlement, it may have also contributed to participants' life trajectories.

\subsubsection{Relationships with Mentors: Linking Social Capital}

Perhaps the most critical relationship participants formed during their association with FUn was with FUn program staff who acted as mentors for them at the time of the program, with some participants stating they are still receiving mentoring support today from those same people. In this section we examine how participants' relationships with mentors created linking social capital (Woolcock, 2001). Mentors in particular helped participants connect to educational and employment institutions outside of their existing cultural, ethnic, and geographical communities.

The mentoring in FUn is informal and there is no set timeframe for mentoring to occur. Mentoring relationships are developed organically through participants working alongside FUn program staff in the various program elements. FUn participants suggested that trust, built through a sustained period of time, was a critical component in the success of their mentoring relationships. Participants viewed the constant positive reinforcement from FUn team members as being instrumental in building confidence and belief in themselves to achieve their personal goals. Participants spoke of hav- 
ing absolute trust in the FUn team, relying on them for support and guidance, and being able to turn to them for support when experiencing hardship and challenges. Participants provided numerous examples of how their FUn mentors assisted them in their long-term development. One example was described by Aliyah, who following her participation in FUn received a prestigious scholarship to attend an American university to play football and study:

I know (FUn team members) played a massive role into probably where I am at the moment... when I first got into FUn I was pretty shy and quiet and I liked football, but I didn't think I was any good at it. I was constantly being called by [FUn team member] and she'll say: "You're good at it." And even with other aspects of my life they were constantly encouraging me to go out there and put my full potential into things....Just listening to them constantly telling me all the positive things is probably one of the main reasons I'm able to achieve so many things today. (Aliyah)

Like Aliyah, other participants talked about how their relationships with FUn mentors were influential in what they have achieved both educationally and professionally. Table 1 highlights that all 20 participants were either engaged in full time study or employment at the time of the interview. Participants went on to study and develop careers predominantly in the allied health, education, and welfare professions. Other participants pursued careers as varied as law, engineering, arts, and trade industries. Several participants detailed how FUn mentors helped connect them to educational and career pathways. This was achieved through identifying individual passions, then supporting and connecting participants to a pathway that would lead them to reach their goals. Aamira provides a clear example of this:

I was very lucky to get the first ever football scholarship from FUn/UNSW [University of New South Wales]....I guess that was the key success to me. I knew I wasn't going to get enough ATAR [Australian Tertiary Admission Rank] to get me into university. I really didn't know where I was going. So, when I received that scholarship I was like, this is my chance to do something in academia in the future and to maybe get a degree. I decided on Sociology, Anthropology and Development Studies. Those three majors led to the community work. I've always had that idea of working with the community and it's not nationally, I would want to work internationally as well. So, that was the start of it. (Aamira)

Aamira was born in and spent the first 10 years of her life in a refugee camp in Kenya. Both Aamira's parents died in her early childhood and she came to Australia at the age of 10 with the support of a family member. At the time of her interview for this study Aamira was completing her master's degree in international development, working as a refugee resettlement worker, and had created a fashion event promoting and celebrating African women and diversity. Since her interview for this study Aamira has started a PhD in international development. Aamira credits FUn mentors with 'kick-starting' her career: "To be honest, if I didn't get involved with FUn, I wouldn't know where I would be. I definitely credit FUn to my success in terms of pointing me to directions and making me focus."

Aamira and Aliyah provide examples of how FUn was able to support participants to connect to an education and career pathway, and this echoes other participant's experiences. The relationships created between participants and their FUn mentors can be viewed as a form of linking social capital (Woolcock, 2001). FUn mentors helped participants make 'vertical connections' to education and employment opportunities (Szreter \& Woolcock, 2004; Woolcock, 2001). These opportunities may have been out of reach of participants lacking in social capital resources prior to their involvement in the FUn program, as many of these opportunities existed outside their cultural, ethnic and geographic communities (Szreter \& Woolcock, 2004; Woolcock, 2001) and may not have been part of their imagined future. FUn mentors helped participants to unlock resources and power within society, accessing educational and vocational opportunities that they may not have been able to access without these relationships (Woolcock, 2001).

FUn did not set out to achieve system wide structural change; and therefore the influence of the program remains open to critique from SFSC scholars who suggest social capital is used to maintain a social structure of inequality and promote a neo-liberal ideology (Blackshaw \& Long, 2005; Darnell, 2012; Kay \& Bradbury, 2009; Spaaij, 2009). Instead FUn aimed to provide opportunities for young people from disadvantaged and diverse backgrounds to fully participate in the society in which they live. The results in this section suggest participants did benefit by enhancing their linking social capital, which was achieved by investing in relationships that linked them to opportunities within the broader social structure of society. While not creating societal change, participants view FUn as being instrumental in providing linking opportunities that changed the trajectory of their lives.

It is important to note that FUn's influence on the development of linking social capital was not achieved by chance. As detailed in the program description, the program considers mentoring to be an integral mechanism of the program, as is creating linkages between program participants and a range of community and organisational stakeholders. Linking participants to institutions and agencies in the education, community services, government, and corporate sectors is viewed by FUn as being critical in providing their young participants with opportunities and networks for longer-term development (Bunde-Birouste, 2013). 


\subsubsection{Giving Back to Community: Reciprocity and} Bounded Solidarity

In this section we examine participants' long-term commitment to 'give back' to their local communities, a key finding in the analysis of participant interviews. Participants did this by either staying involved in FUn, developing other community projects, or going onto tertiary study, or careers in social justice, welfare, health, or education fields. The following discussion is framed by key social capital concepts of reciprocity and bounded solidarity (Portes, 1998; Putnam, 2000).

Not all participants were involved in community activities at the time of their interviews for this study. Majeeda started studying social work full time and working in childcare left her little opportunity for participation in activities in her geographical community. Asim also suggested his work as an actor, including constant travel, impacted on his ability to be involved in communitybased activities. However, for the remaining 18 participants there was a strong connection and involvement in their local geographic, cultural, and ethnic communities.

Medi is currently completing a bachelor's degree in education, works part time in childcare, and is involved in her local Congolese community providing information and education sessions for those that have recently resettled in Australia. Throughout her interview, Medi demonstrated a commitment and motivation to give back, utilising the experience and skills she has developed to make a difference in the lives of others:

In Uganda we lived in a refugee camp which meant we didn't have any early childhood education or early primary school education. My dream was to just go to school and study, then eventually when I came to Australia...I had that opportunity to study and once I finished high school I was just interested in learning and eventually...teach my knowledge to others. Then eventually l'll go back to my country and teach young children like myself who don't have those opportunities to get an education, especially young girls.

Medi's experiences are consistent with the majority of participants in the study. Participant interviews suggest that while FUn developed skills and helped them on their career pathways, it was also their childhood experiences of trauma, disadvantage and displacement that led to a passion for creating social change. It appears that participants lived experience created a drive to contribute to others by helping those who had also experienced similar challenges in their lives enabled in part by the confidence and skills they developed in FUn.

Ram who arrived in Australia following many years living in a refugee camp in Nepal, is currently working as an electrical engineer, and used the experiences he obtained from FUn to organise SFSC programs and events within this community. He described in his interview a commitment to utilise the skills and knowledge he has gained through life experience and formal study to make a difference not only in his ethic community in Australia, but also by returning to Nepal:

Yeah, that's been my passion and I always wanted to be an engineer and do something with electricity especially from the background that I come from. I come from Nepal...there is not much infrastructure...there is not much electricity production going on there. Since I was young I always (wanted) to go into the energy field and make some contribution to the country...because I came from there, I still pursue that dream. (Ram)

Some participants explained how they were currently utilising their FUn experience to launch projects within their own local communities. Dance classes, youth education groups, and SFSC projects, were just a few of the varied projects and programs that former FUn participants were running in their own communities. Participants that had created their own programs or were working to create social change were asked what it meant to them to 'give back.' Consistently participants suggested it had significant meaning because of their childhood experiences, helping others in similar circumstances was their driving force. Some participants suggested because they were helped and were given opportunities by FUn they were determined to provide others with similar opportunities, which is described by Grace:

I think its experience...once you've experienced something and you understand that you're blessed to be where you are, you will really want to give back. And just appreciation of where you are today makes you want to do something for other people.

Social capital literature often cites 'norms of reciprocity' as an integral component in creating social capital in communities (Putnam, 2000). On the surface this could help to explain participant's motivations to 'give back'; as they were provided support in their resettlement, they wanted to reciprocate by providing support to others experiencing similar circumstances. However, this does not appear to adequately reflect participants' deep motivation and determination to make a difference within their geographic, ethnic, and cultural communities. A deeper look at the social capital literature, and particularly scholars who have focused on diverse communities such as refugees and immigrants, provides a stronger explanation. Portes (1998, p. 8) suggests 'giving back' is stronger in immigrant communities due to what he terms 'bounded solidarity.' This is created within groups who share similar experiences of disadvantage based on cultural and religious ties, and in the case of the current study a shared experience of trauma and displacement. These communities often share a strong sense of belonging and obligation (Portes, 1998). Gomez et al. (2015) 
used the term principled motivation to describe actions that have a positive impact on individuals or communities, are usually voluntary, and are performed with no expectation of being rewarded. Gomez et al. (2015) suggested actions arising from principled motivation are guided by individual and collective values or having a sense of belonging to a group.

'Bounded solidarity' and 'principled motivation' provide an explanation of participants' need to 'give back' to their local communities. Participant's life experiences of trauma and displacement appeared to create a bounded solidarity with their communities. We argue here, based on participant interviews that FUn played a pivotal role in fostering the principled motivation that led participants to 'give back.' FUn provided a sense of belonging to participants. FUn also provided mentoring, developed life skills, and provided opportunities for participation in community based and international social change initiatives. These various program elements provided participants with the knowledge and skill set to be able to pursue social change activities aligned with their individual values following program involvement. As stated above, FUn did not set out to create system wide societal change, yet some participants made a significant contribution to the communities in which they lived. In this way, the results respond to some of the critique of social capital in the SFSC literature, by showing that programs may benefit an individual through access to social capital and in turn these individuals will help provide similar benefits to their wider communities (Darnell, 2012). By 'giving back' to their geographic, cultural, and ethnic communities, participants in this study were demonstrating the potential that SFSC programs have to create change beyond the individual.

\subsubsection{Personal Development}

While participants in this study perceived the relationships, they formed through FUn as being instrumental to their long-term development, they also viewed the program as contributing to the development of life skills which continue to be used today. One example used by several participants was the development of leadership skills. Skill building through leadership focused workshops, camps, international events, and football coaching training, provided multiple opportunities for participants to develop leadership skills. A number of participants reported it was the leadership skills they acquired through FUn that led to them undertaking long-term leadership roles within their geographical, ethnic, and cultural communities. Another personal development outcome that was consistent amongst several participants was an increase in confidence. These participants described their participation in a variety of FUn life-skill activities had increased their confidence which had a positive impact on developing relationships, communicating with a wide range of audiences, presenting their ideas, and developing social change initiatives.
While it is outside the scope of this article, it is recommended that further research examines personal development outcomes and how they are influenced by the various program elements of youth-focused SFSC programs.

\subsubsection{Limitations}

While this study has provided new insights to the field by examining participant perceptions of whether and how youth-focused SFSC programs have influenced their life trajectories, there are several limitations. Firstly, this study relied on the individual perceptions of 20 young people who participated in the program. While sample size can be a contentious issue the research team was guided by Terry et al. (2017) who suggest between 15-20 qualitative interviews is appropriate for an exploratory study. The research team also considers the sample size of a mix of moderately and highly engaged participants in the FUn program as being appropriate for an explorative study, and important in identifying whether these programs have the potential to influence the life trajectories of young people. While the findings may not be transferrable to all young people who attend the FUn program, nor generalizable to other programs, the potential influence of such programs on the lives of moderately and highly engaged participants is illuminated by the study findings. In particular the changes in bridging and linking social capital, reciprocity and bounded solidarity are worthy of further study and investigation.

Secondly it is probable that participants that chose to respond and participate in interviews for this study were motivated to participate because of a positive connection to the program, and because they consider themselves to be 'on-track' with their lives. Former FUn participants who had less of a connection to the program, or who had considered themselves not to be 'on-track' in their lives may not have been motivated to participate.

Finally, we wish to note the limitations and challenges of the retrospective approach taken in this study. There are many factors influencing the life trajectories of young people, and it is not possible to provide causal evidence of the long-term influence of such programs without a longitudinal experimental research design. Doing so may also assist scholars in the area to further develop conceptual and theoretical frameworks to better explain the mechanisms by which these programs deliver benefits to young people and society more broadly. However, in the absence of such a study design it remains critical to start to understand the potential long-term influence of youth focused SFSC programs. The voices of participants in this study should not be undervalued in achieving these goals. Further qualitative and quantitative research is being planned to test this explorative phase and further examine these important areas of practice and research. 


\section{Conclusion}

This study set out to examine whether and how former FUn participants perceived the program had influenced their life trajectories. The findings demonstrate that participants did perceive that the program had influenced their life trajectories in positively described ways. The relationships participants formed through FUn had the greatest impact, in particular for participants who had experienced displacement and trauma as refugees prior to resettlement in Australia. Creating and sustaining bridging social capital, through relationships within and outside of their cultural and ethnic communities created a sense of belonging in Australia and longer-term connections for some participants. Findings also suggest the mentoring relationships between participants and FUn program staff created linking social capital which set them on a path to pursuing their educational and career goals. The study also argues the FUn program influenced participants' motivation to embrace a long-term commitment to 'give back' to their local cultural, ethnic, and geographical communities.

The findings are important for youth-focused SFSC programs. This study suggests these programs have the potential to positively influence the life trajectories of at least some participants. The findings of this study could be used to inform future long-term impact studies. The study could also inform the implementation and design of youth-focused SFSC programs to include active strategies to enhance bridging and linking social capital, particularly for young people from disadvantaged and diverse backgrounds.

\section{Conflict of Interests}

The authors declare no conflict of interests.

\section{References}

Adams, A., Harris, K., \& Lindsey, I. (2017). Examining the capacity of a sport for development programme to create social capital. Sport in Society, 21(3), 558-573.

Ager, A., \& Strang, A. (2004). Indicators of integration: Final report (Development and Practice Report 28). London: Home Office.

Ager, A., \& Strang, A. (2008). Understanding integration: A conceptual framework. Journal of Refugee Studies, 21(2), 166-191.

Blackshaw, T., \& Long, J. (2005). What's the big idea? A critical exploration of the concept of social capital and its incorporation into leisure policy discourse. Leisure Studies, 24(3), 239-258.

Bourdieu, P. (1986). The forms of capital. In J. Richardson (Ed.), Handbook of theory and research for the sociology of education (pp. 241-258). New York, NY: Greenwood Press.

Braun, V., \& Clarke, V. (2006). Using thematic analysis in psychology. Qualitative Research in Psychology, 3(2), 77-101.

Braun, V., \& Clarke, V. (2019). Reflecting on reflexive thematic analysis. Qualitative Research in Sport, Exercise and Health, 11(4), 589-597.

Braun, V., Clarke, V., \& Terry, G. (2015). Thematic analysis. In P. Rohleder \& A. Lyons (Eds.), Qualitative research in clinical and health psychology (pp. 95-113). Basingstoke: Palgrave MacMillan.

Bunde-Birouste, A. (2013). Kicking goals for social change (Unpublished Doctoral dissertation). University of New South Wales, Sydney, Australia.

Bunde-Birouste, A., Nathan, S., McCarroll, B., Kemp, L., Shwe, T., \& Grand Ortega, M. (2012). Playing for change. Sydney: School of Public Health and Community Medicine.

Coakley, J. (2011). Youth sports: What counts as "positive development"? Journal of Sport \& Social Issues, 35(3), 306-324.

Coalter, F. (2010). Sport-for-development: Going beyond the boundary? Sport in Society, 13(9), 1374-1391.

Coalter, F. (2013). Sport for development: What game are we playing? London: Routledge.

Coalter, F. (2015). Sport-for-change: Some thoughts from a sceptic. Social Inclusion, 3(3), 19-23.

Coleman, J. S. (1994). Foundations of social theory. Cambridge, MA: Harvard University Press.

Correa-Velez, I., Gifford, S. M., \& Barnett, A. G. (2010). Longing to belong: Social inclusion and wellbeing among youth with refugee backgrounds in the first three years in Melbourne, Australia. Social Science \& Medicine, 71(8), 1399-1408.

Correa-Velez, I., Gifford, S. M., McMichael, C., \& Sampson, R. (2016). Predictors of secondary school completion among refugee youth 8 to 9 years after resettlement in Melbourne, Australia. Journal of International Migration and Integration, 18(3), 791-805.

Darnell, S. C. (2012). Sport for development and peace: A critical sociology. London: Bloomsbury.

Field, J. (2003). Social capital. London: Routledge.

Gomez, C., Perera, B. Y., Weisinger, J. Y., Tobey, D. H., \& Zinsmeister-Teeters, T. (2015). The impact of immigrant entrepreneurs social capital related motivations. New England Journal of Entrepreneurship, 8(2), 19-30.

Hoekman, M. J., Schulenkorf, N., \& Welty Peachey, J. (2018). Re-engaging local youth for sustainable sportfor-development. Sport Management Review, 22(5), 613-625.

Holt, N. L., Neely, K. C., Slater, L. G., Camire, M., Cote, J., Fraser-Thomas, J., . . . Tamminen, K. A. (2017). A grounded theory of positive youth development through sport based on results from a qualitative meta-study. International Review of Sport and Exercise Psychology, 10(1), 1-49.

Kay, T. (2012). Sport in the service of international development. Criminal Justice Matters, 88(1), 18-19.

Kay, T., \& Bradbury, S. (2009). Youth sport volunteering: 
Developing social capital? Sport, Education and Society, 14(1), 121-140.

Nathan, S., Bunde-Birouste, A., Evers, C., Kemp, L., MacKenzie, J., \& Henley, R. (2010). Social cohesion through football: A quasi-experimental mixed methods design to evaluate a complex health promotion program. BMC Public Health, 10(1), 587-598.

Nathan, S., Kemp, L., Bunde-Birouste, A., MacKenzie, J., Evers, C., \& Shwe, T. (2013). “We wouldn't of made friends if we didn't come to Football United": The impacts of a football program on young people's peer, prosocial and cross-cultural relationships. BMC Public Health, 13, 1-16.

Nathan, S., Newman, C., \& Lancaster, K. (2018). Qualitative interviewing. In P. Liamputtong (Ed.), Handbook of research methods in health social sciences (pp. 391-410). Singapore: Springer.

Neale, J., Tompkins, C. N. E., \& Strang, J. (2018). Qualitative exploration of relationships between peers in residential addiction treatment. Health \& Social Care in the Community, 26(1), 39-46.

Patton, M. Q. (2015). Qualitative research and evaluation methods (4th ed.). Thousand Oaks, CA: Sage Publications.

Portes, A. (1998). Social capital: It's origins and applications in modern sociology. Annual Review of Sociology, 241(1), 1-24.

Putnam, R. D. (2000). Bowling alone: The collapse and revival of American community. New York, NY: Simon \& Schuster.

Sherry, E. (2010). (Re)engaging marginalized groups through sport: The homeless World Cup. International Review for the Sociology of Sport, 45(1), 59-71.

Sherry, E., Schulenkorf, N., \& Chalip, L. (2015). Managing sport for social change: The state of play. Sport Management Review, 18(1), 1-5.

Spaaij, R. (2009). Sport as a vehicle for social mobility and regulation of disadvantaged urban youth: Lessons from Rotterdam. International Review for the Sociology of Sport, 44(2/3), 247-264.

Spaaij, R. (2011). Sport and social mobility. New York, NY: Routledge.

Spaaij, R. (2012). Building social and cultural capital among young people in disadvantaged communities: Lessons from a Brazilian sport-based intervention program. Sport, Education and Society, 17(1), 77-95. Spaaij, R. (2013). Changing people's lives for the better? Social mobility through sport-based intervention programmes: Opportunities and constraints. European Journal for Sport and Society, 10(1), 53-73.

Spaaij, R. (2014). Refugee youth, belonging and community sport. Leisure Studies, 34(3), 303-318.

Szreter, S., \& Woolcock, M. (2004). Health by association? Social capital, social theory, and the political economy of public health. International Journal of Epidemiology, 33(4), 650-667.

Terry, G., Hayfield, N., Clarke, V., \& Braun, V. (2017). Thematic analysis. In C. Willig \& W. Rogers (Eds.), The Sage handbook of qualitative research in psychology (pp. 17-37). London: Sage.

United Nations Department of Economic and Social Affairs. (2016). Leaving no one behind: The imperative of inclusive development. Report on the world social situation 2016. New York, NY: United Nations Department of Economic and Social Affairs.

Weiss, M. R., Bolter, N. D., \& Kipp, L. E. (2016). Evaluation of the first tee in promoting positive youth development: Group comparisons and longitudinal trends. Research Quarterly for Exercise and Sport, 87(3), 271-283.

Welty Peachey, J., Cohen, A., Borland, J., \& Lyras, A. (2011). Building social capital: Examining the impact of Street Soccer USA on its volunteers. International Review for the Sociology of Sport, 48(1), 20-37.

Whitley, M. A., Massey, W. V., \& Farrell, K. (2017). A programme evaluation of 'exploring our strengths and our future': Making sport relevant to the educational, social, and emotional needs of youth. Journal of Sport for Development, 5(9), 21-34.

Whitley, M. A., Massey, W. V., \& Wilkison, M. (2018). A systems theory of development through sport for traumatized and disadvantaged youth. Psychology of Sport and Exercise, 38, 116-125.

Woolcock, M. (2001). The place of social capital in understanding social and economic outcomes. ISUMA, Canadian Journal of Policy Research, 2(1), 11-17.

Zimmerman, M. A. (2013). Resiliency theory: A strengthsbased approach to research and practice for adolescent health. Health Education \& Behavior, 40(4), 381-383.

\section{About the Authors}

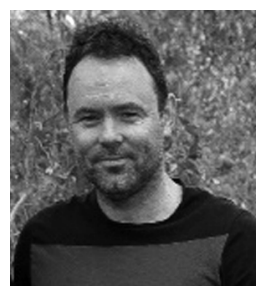

Rob Cunningham is a PhD Candidate in the School of Public Health and Community Medicine at the University of New South Wales. For the past two decades he has worked in direct social work practice specialising in working with young people experiencing trauma. 

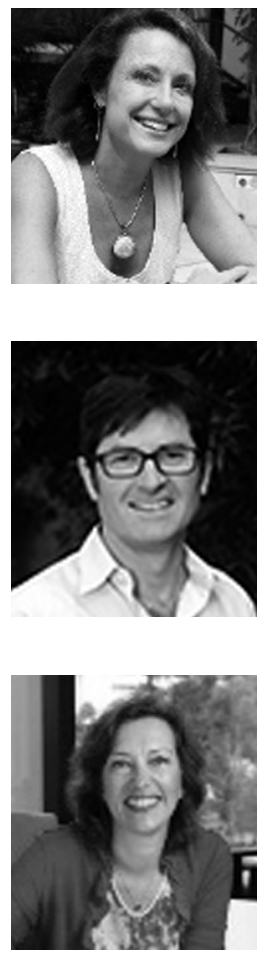

Anne Bunde-Birouste is an International Expert in health promotion, sport for social change and practice-based research, with particular focus on innovative health promotion approaches with youth, disadvantaged groups, and communities.

Patrick Rawstorne is a Researcher, Higher Education Educator, Psychometrician, and an AHPRA registered Psychologist. He has particular research interests in structural disadvantage and inequity, as well as in mental health.

Sally Nathan is a Public Health Social Scientist who partners with health services and NGOs to improve equity and access for young people, disadvantaged groups, and communities. 